\title{
Ecosystem Services, Governance, and Stakeholder Participation: an Introduction
}

\author{
Jouni Paavola $^{1}$ and Klaus Hubacek ${ }^{2}$
}

Key Words: adaptive; ecosystem services; governance; participation; payment for ecosystem services; protected areas; resilience; social-ecological systems; stakeholders

\section{ECOSYSTEM SERVICES, GOVERNANCE, AND STAKEHOLDER PARTICIPATION: AN INTRODUCTION}

The ecosystem services approach has gained popularity, and novel incentive-based ecosystem conservation strategies are increasingly being used. This calls for the reassessment and transformation of conceptual-theoretical, natural resource management, and governance approaches to conservation. In the past, conservation efforts focused on distinct components of ecosystems without regard for long-term human well-being. Natural resource management in turn sought to control nature to harvest products for direct consumption or for sale at markets. However, this singular focus on management ignored that ecosystems are complex, dynamic, adaptive systems with nonlinear feedback and thresholds (Costanza 2008) and are tightly interlinked with human systems (Menzel and Teng 2010).

Since the 1970s (Holling 1973, 1978), awareness has increased about the negative and unexpected social and environmental problems caused by attempts to control highly complex and nonlinear natural systems (Holling and Meffe 1996). Conventional command-and-control resource management has also become increasingly criticized (e.g., Holling and Meffe 1996, Wondolleck and Yaffee 2000, Folke et al. 2005), and new innovative approaches have emerged for understanding and managing social-ecological systems. For example, the ecosystem services approach currently informs the development of environmental accounting and performance systems (Boyd and Banzhaf 2007), economic valuation for environmental decision making, planning and policy (Balmford et al. 2002, Turner et al. 2003), equity in human welfare (see Wallace 2007), landscape management, adaptive governance (Folke et al. 2005), and attainment of multiple conservation objectives (Fisher et al. 2009).

The ecosystem services approach acknowledges the complex interactions between the structures, processes, and services of an ecosystem across the landscape (Turner and Daily 2008, Fisher et al. 2009). Although there are synergies between some services, trade-offs exist between others. Ecosystem service trade-offs arise when the provision of one service is enhanced at the cost of reducing the provision of another service, and ecosystem service synergies arise when multiple services are enhanced simultaneously (MEA 2005, Raudsepp-Hearne et al. 2010). Bennett et al. (2009) have presented a conceptual framework for understanding the drivers, trade-offs, and synergies between services. The trade-offs between disparate and changing social goals require the resolution of conflicts, which is replete with power and resource inequalities, asymmetric distribution of incomplete information, and unequal outcomes (Paavola 2007, Robards et al. 2011). Conflict resolution processes demand a better understanding of ecological functioning, social structures, and stakeholder participation, as well as dynamic interactions in these socialecological systems (Paavola et al. 2009). An important prerequisite for assessing synergies and trade-offs between ecosystem services is an understanding of which ecosystem services are provided and where. A number of national, regional, and global ecosystem service assessments, such as the United Kingdom National Ecosystem Assessment, the Economics of Ecosystems and Biodiversity initiative, and the Millennium Ecosystem Assessment have sought to provide such baseline information (see also, e.g., Costanza et al. 1997, Fisher and Turner 2008).

Thus, it is necessary to understand and enhance the adaptability and resilience of social-ecological systems in the face of disturbances, fluctuation of ecosystem services, changing societal preferences, needs of local communities and other stakeholders, and distributional impacts of different management options and governance regimes (Hubacek et al. 2009). Biggs et al. (2012) have identified seven principles for enhancing the resilience of ecosystem services, which focus on generic social-ecological systems properties and processes and on the way they are governed. The ecosystems service approach has the potential to lead to a better understanding and management of natural resources. However, because of the complexity of social-ecological systems, there will always remain uncertainty regarding causal relationships within ecological systems and their responses to external drivers. In addition, the systems' boundaries are not "set in stone"; they remain open to definition of who the stakeholders are in a continuum from local communities maintaining their livelihoods based on traditional resource extraction to urban consumers of services or international stakeholders. This is 
especially the case with tropical forests, which importantly support local livelihoods but also cater to the global need for carbon sequestration (Chhatre and Agrawal 2009).

The previous discussion highlights two principal elements of the management of social-ecological systems: the systems to be governed and the system of governance. This Special Feature brings together 10 articles, which in different ways critically address social-ecological systems and their governance, with an emphasis on the role and modes of participation in governance and ways to facilitate these processes. The majority of the articles formed a part of a special session on "Governance of Ecosystem Services" at the International Society for Ecological Economics conference in Bremen, Germany, on 22-25 August 2010. The articles address the conceptual and methodological problems in the governance of ecosystem services, distributional aspects of ecosystem services and policies to achieve the provision of ecosystem services, institutional fit and design in a context of diverse spatial boundaries of different ecosystem services and the multitude of stakeholders in an ecosystem service catchment, governance of ecosystem services, and larger socioeconomic trends and transformations. Thus, the Special Feature provides critical counterpoints to the often uncritical discussion of ecosystem services, as well as examples of applications in very different socioeconomic and biophysical contexts.

This Special Feature starts from the assumption that the application of the ecosystem service approach implies a more critical focus on environmental governance and participation (Wesselink et al. 2011) and on the complex, adaptive functioning of ecosystems and the consideration of uncertainties prevalent at various spatial and temporal scales. This requires a shift in how governance systems should be designed for managing natural resources under uncertainty, by considering power and distributional issues, taking to account broader participation, and reconceptualizing socialecological systems so as to anticipate changes and take steps to either reduce their probability or minimize their impact once they occur.

Empirical studies suggest that successful ecosystem change, resource management, and implementation of resilience/ coping strategies can be achieved only when social and ecological systems are interlinked (Rechkemmer and von Falkenhayn 2009, Biggs et al. 2012). Menzel and Teng (2010) have emphasized that the human dimension has to be included early and explicitly in ecosystem service projects, for example, through the involvement of stakeholders in research. On the other hand, Folke et al. (2004) and Kenward et al. (2011) have suggested that active adaptive management and governance of resilience will be required to sustain desired ecosystem states and to transform degraded ecosystems into more desirable states. Notwithstanding advances in this area, we still have disjointed knowledge, and there is much uncertainty about how different kinds of governance structures, levels of participation, and adaptive strategies affect ecosystems.

In this Special Feature, Mauerhofer et al. (2013) review the paradigm shift in natural resource management from the polluter pays principle (PPP), focusing on polluters and enforcement of thresholds, to the principle of payment for ecosystem services (PES), under which the beneficiaries of environmental services have to pay. The question they address is whether society should have the right to freely available and clean environments or whether people should be required to pay for them just like any other commodities they consume. The authors trace the reframing of the debate by investigating the literature and current policies. They discuss the PPP and the "provider-gets-paid" approaches with regard to economic efficiency, ecologically sustainable scale and inherent qualities of ecosystems, and distributional effects. The coexistence, potential complementarities, and replacement of one principle by the other are discussed in different contexts. Their conclusion is that insufficient attention has been paid to the fact that by replacing the earlier PPP doctrine with the provider-gets-paid principle, rights are redistributed from the public to the service provider with important distributional implications for society. Therefore, this shift in policy paradigms includes obstacles as well as opportunities, in particular for the relationships between the rich and the poor and between developing and developed countries.

In the face of the spread of PES as a tool to ensure the protection of global ecosystems and poverty alleviation, we need to consider new governance structures and the associated risks within which ecosystem services will be managed. Following a precautionary approach, Kronenberg and Hubacek (2013) investigate ways in which the rapid development of PES can negatively influence regional and national economies. Drawing from the resource curse literature, the authors point out that resource revenues are highly correlated with economic problems in poor countries that are not able to use those revenues to ensure sound development. Problems similar to those that affect resource-rich countries may emerge in the case of economies rich in ecosystem services once PES increases in spatial and monetary scales. The most prominent examples of such problems include rent seeking, unequal bargaining power of buyers and sellers, and volatility of payments, which are all related to the quality of institutions. Kronenberg and Hubacek conclude that to ensure long-term positive impacts of PES, such systems should be carefully designed, paying particular attention to distribution of property rights and transparency, decentralization of revenues, and capacity building to ensure further development opportunities.

As mentioned previously, ecosystem services are not isolated from each other; they interact in a complex and dynamic 
manner. The interplay of ecosystem services, generating synergies and trade-offs, will depend greatly on the human dimension of any social-ecological system. Reed et al. (2013) explore stakeholder participation in ecosystem services management in light of the evidence from the Rural Economy and Land Use Programme's Sustainable Uplands project in the United Kingdom. Their article shows how computer models developed in close collaboration with decision makers and other stakeholders can help identify potential trade-offs and complementarities between different ecosystem services, so that policies can be designed to avoid the worst trade-offs and, where possible, enhance multiple services. One of the unique contributions of Reed et al. is the finding that by engaging collaborators and covering a wide a range of future scenarios, it may be possible for decision makers to act rapidly and effectively to protect and enhance the provision of ecosystem services in the face of unpredictable future change. The authors also broke new ground in creating social learning opportunities in multiple ways and by communicating research results not only through publishing in research outlets but also through broadcasting documentaries, publishing a children's book, and creating an uplands song.

Reduced emissions from deforestation and forest degradation (REDD+) is a PES that has recently received strong support as a potential component of the future global climate change policy. However, as the contributions by Rendón Thompson et al. (2013) and Watson et al. (2013) show, there is a high degree of uncertainty in the costs of achieving emission reductions through REDD+. Rendón Thompson et al. (2013) assess the transaction costs of six REDD+ project designs from the Peruvian Amazon and compare them with those of established projects in Brazil and Bolivia. Their findings show that the costs of implementing REDD+ are highly uncertain for participating developing countries because of issues such as inadequate project design and how additionality is determined. Furthermore, the authors provide important insight into how different activities to reduce deforestation and forest degradation, the type of implementer, and project location affect the implementation costs of REDD+ projects. It is disquieting that even with these first estimates, the cost of preserving existing intact forests in the Peruvian Amazon may have been underestimated.

Another article on REDD+ by Watson et al. (2013) assesses the uncertainty in accounting for emission reductions. There is substantial uncertainty in emission reductions accounting because of a lack of forest carbon stock data from developing countries, where the application of biome-averaged data over large forest areas is commonplace. Using a case study in the Bale Mountains in Ethiopia, the authors exemplify the implications of forest carbon stock estimates on predicted REDD+ project emission reductions and revenues. Findings indicate that biome-averaged data reported by the Intergovernmental Panel on Climate Change severely underestimate forest carbon stock in their study site compared to estimates based on primary data. Combining forest carbon stock estimates and uncertainty in voluntary carbon market prices demonstrates the financial impact of uncertainty. These findings are important because estimated revenues will influence decisions on whether to implement a project and may have profound implications for the level of benefit sharing that can be supported. Thus, strong financial incentives exist to improve ecological knowledge of ecosystem services such as forest carbon stock estimates in tropical forests.

Mustalahti et al. (2012) examine how local priorities and needs could be met in REDD+ implementation and how these expectations match the global mitigation benefits. The authors examine the local priorities and needs in the use of land and forest resources in two villages of the Angai Villages Land Forest Reserve in Tanzania, based on semistructured key informant interviews, participatory rural appraisal methods, and key informant interviews at different levels. The Angai villagers highlight three key priorities that have yet to be integrated into the design of REDD+: water scarcity, rural development, and food security. At the local level, improved forest governance and sustainable management of forest resources have been identified as one way to achieve livelihood diversification. The main conclusion is that although the national goals of REDD+ include poverty reduction, these goals are not necessarily conducive to the goals of the case study communities. There exist both structural and cultural limits to the ability of the Angai villages to implement these goals and to improve forestry governance.

Three contributions seek to apply the concepts of resilience, vulnerability, and adaptation usually used in the context of climate change to the ecosystem services approach. Although the concept of PES has been extensively scrutinized in terms of its potential for poverty alleviation in developing countries, less attention has been paid to its potential role in adaptation to climate change. To maximize synergies and minimize tradeoffs between PES and adaptation, it is important that the conceptual links between both are made explicit. Van de Sand (2012) discusses the main conceptual links between PES and adaptation to climate change and suggests ways of making PES propoor and proadaptation. The article demonstrates that drawing upon the concepts of vulnerability, adaptive capacity, and social-ecological systems, PES can potentially contribute to adaptation in three main ways: through enhancements in the provision of ecosystem services, by enhancing adaptive capacity in the way PES is designed and implemented, and by providing an incentive mechanism to adopt specific measures for adaptation to climate change.

Another useful application of climate change concepts to a social-ecological system is provided by Tuvendal and Elmqvist (2011), who combine resilience and ecosystem 
service considerations in an empirical case study. The authors assess the drivers and impacts of brownification of the River Helge å catchment in southern Sweden and assess future ecosystem service delivery for stakeholders in downstream areas in combination with climate change projections. Their analysis suggests that extreme water flows in the future may lead to an increase in brownification, with implications on ecosystem services for downstream users and potentially the resilience of the whole biosphere reserve. The new disturbance regime requires new adaptive and coping strategies by local farming and fishing stakeholders. The authors suggest that environmental monitoring of slowly changing variables is crucial but must be linked to ecosystem service benefits to get buy-in from local stakeholders.

Soane et al. (2012) examine the close interaction between alpine pasture ecology and the natural resource management regimes in the cultural landscape of northern Italy. The authors examine the limited literature available on resilience of such landscapes and address gaps in it through the interpretation and use of adaptive cycles provided by the panarchy perspective. The authors show that a panarchy model offers a powerful metaphor with practical implications for the maintenance of such alpine cultural landscapes and provides new insights into the description of and the future options for land use. They show that resilience theory, through its focus on adaptive cycles, interacting at different temporal and spatial scales, offers useful insights into resource management and, in particular, nature conservation sites by focusing more on dynamics than on an optimal assemblage of species. It is further argued that this may help to achieve the objectives of Natura 2000 through the European Habitats Directive.

In contrast to previous contributions, which focus on the relationship between climate change and social-ecological systems, Niedzialkowski et al. (2012) explore the effectiveness of changing modes of participation in protected area governance, discussing the limitations and problems of public participation. Their case study of the Bialowieza Primeval Forest between 1918 and 2010 demonstrates that power relations, a lack of a deliberative rationale, and instrumental reasons constituted the main drivers of the changing patterns of participation. As a result, conservation goals were only partially achieved. Their findings highlight that when interests are clearly conflicting and win-win solutions are difficult to reach, room for constructive participation may be limited. In these circumstances, public involvement may turn into yet another venue for a power play between actors with vested interests, without bringing gains in legitimacy or new policy options. Their study shows that this is especially the case for countries with a relatively short democratic record where the government lacks the consistency and capacity to steer the process over the longer term.
All contributions to this Special Feature illustrate in different ways how enhancing the understanding of the governance of ecosystem services is crucial for ensuring that socialecological systems are managed to face current global change. This Special Feature is but one step in an ongoing effort to understand these relationships, and we hope it will inspire more researchers to take on this much-needed and timely challenge.

Responses to this article can be read online at: http://www.ecologyandsociety.org/issues/responses. php/6019

\section{Acknowledgments:}

We gratefully acknowledge the assistance of Olivia Rendon in the preparation of this editorial. Jouni Paavola also acknowledges the support of the UK Economic and Social Research Council for the Centre for Climate Change Economics and Policy and for his contribution to this work.

\section{LITERATURE CITED}

Balmford, A., A. Bruner, P. Cooper, R. Costanza, S. Farber, R. E. Green, M. Jenkins, P. Jefferiss, V. Jessamy, J. Madden, K. Munro, N. Myers, S. Naeem, J. Paavola, M. Rayment, S. Rosendo, J. Roughgarden, K. Trumper, and R. K. Turner. 2002. Economic reasons for conserving wild nature. Science 297:950-953.

Bennett, E. M., G. D. Peterson, and L. J. Gordon. 2009. Understanding relationships among multiple ecosystem services. Ecology Letters 12:1394-1404. http://dx.doi. org/10.1111/j.1461-0248.2009.01387.x

Biggs, R., M. Schlüter, D. Biggs, E. L. Bohensky, S. BurnSilver, G. Cundill, V. Dakos, T. M. Daw, L. S. Evans, K. Kotschy, A. M. Leitch, C. Meek, A. Quinlan, C. RaudseppHearne, M. D. Robards, M. L. Schoon, L. Schultz, and P. C. West. 2012. Toward principles for enhancing the resilience of ecosystem services. Annual Review of Environment and Resources 37:421-448. http://dx.doi.org/10.1146/annurevenviron-051211-123836

Boyd, J., and S. Banzhaf. 2007. What are ecosystem services? The need for standardised environmental accounting units. Ecological Economics 63:616-626. http://dx.doi.org/10.1016/ j.ecolecon.2007.01.002

Chhatre, A., and A. Agrawal. 2009. Trade-offs and synergies between carbon storage and livelihood benefits from forest commons. Proceedings of the National Academy of Sciences 
of the United States of America 106(42):17667-17670. http:// dx.doi.org/10.1073/pnas.0905308106

Costanza, R. 2008. Ecosystem services: multiple classification systems are needed. Biological Conservation 141:350-352. http://dx.doi.org/10.1016/j.biocon.2007.12.020

Costanza, R., R. d'Arge, R. de Groot, S. Farber, M. Grasso, B. Hannon, K. Limburg, S. Naeem, R. V. O'Neill, J. Paruelo, R. G. Raskin, P. Sutton, and M. van den Belt. 1997. The value of the world's ecosystem services and natural capital. Nature 387:253-260. http://dx.doi.org/10.1038/387253a0

Fisher, B., and R. K. Turner. 2008. Ecosystem services: classification for valuation. Biological Conservation 141:1167-1169. http://dx.doi.org/10.1016/j.biocon.2008.02.019

Fisher, B., R. K. Turner, and P. Morling. 2009. Defining and classifying ecosystem services for decision making. Ecological Economics 68:643-653. http://dx.doi.org/10.1016/ j.ecolecon.2008.09.014

Folke, C., S. Carpenter, B. Walker, M. Scheffer, T. Elmqvist, L. Gunderson, and C. S. Holling. 2004. Regime shifts, resilience, and biodiversity in ecosystem management. Annual Review of Ecology, Evolution and Systematics 35:557-581. http://dx.doi.org/10.1146/annurev.ecolsys.35.021103.105711

Folke, C., T. Hahn, P. Olsson, and J. Norberg. 2005. Adaptive governance of social-ecological systems. Annual Review of Environment and Resources 30:441-473. http://dx.doi. org/10.1146/annurev.energy.30.050504.144511

Holling, C. S. 1973. Resilience and stability of ecological systems. Annual Review of Ecological Systems 4:1-23. http:// dx.doi.org/10.1146/annurev.es.04.110173.000245

Holling, C. S. 1978. Adaptive environmental assessment and management. John Wiley and Sons, New York, New York, USA.

Holling, C. S., and G. K. Meffe. 1996. Command and control and the pathology of natural resource management. Conservation Biology 10(2):328-337. http://dx.doi. org/10.1046/j.1523-1739.1996.10020328.x

Hubacek, K., N. Beharry, A. Bonn, T. Burt, J. Holden, F. Ravera, M. Reed, L. Stringer, and D. Tarrasón. 2009. Ecosystem services in dynamic and contested landscapes: the case of UK uplands. Pages 167-188 in M. Winter and M. Lobley, editors. What is land for? The food, fuel and climate change debate. Earthscan, London, UK.

Kenward, R. E., M. J. Whittingham, S. Arampatzis, B. D. Manos, T. Hahn, A. Terry, R. Simoncini, J. Alcorn, O. Bastian, M. Donlan, K. Elowe, F. Franzén, Z. Karacsonyi, M. Larsson, D. Manou, I. Navodaru, O. Papadopoulou, J. Papathanasiou,
A. von Raggamby, R. J. A. Sharp, T. Söderqvist, A Soutukorva, L. Vavrova, N. J. Aebischer, N. Leader-Williams, and C. Rutz. 2011. Identifying governance strategies that effectively support ecosystem services, resource sustainability, and biodiversity. Proceedings of the National Academy of Sciences of the United States of America 108(13):5308-5312. http://dx.doi.org/10.1073/pnas.1007933108

Kronenberg, J., and K. Hubacek. 2013. Could payments for ecosystem services create an "ecosystem service curse"? Ecology and Society 18(1): 10. http://dx.doi.org/10.5751/ ES-05240-180110

Mauerhofer, V., K. Hubacek, and A. Coleby. 2013. From polluter pays to provider gets: distribution of rights and costs under payments for ecosystem services. Ecology and Society 18(4): 41. http://dx.doi.org/10.5751/ES-06025-180441

Menzel, S., and J. Teng. 2010. Ecosystem services as a stakeholder-driven concept for conservation science. Conservation Biology 24(3):907-909. http://dx.doi.org/10.1111/ j.1523-1739.2009.01347.x

Millennium Ecosystem Assessment (MEA). 2005. Ecosystems and human well-being: synthesis. Island, Washington, D.C., USA.

Mustalahti, I., A. Bolin, E. Boyd, and J. Paavola. 2012. Can REDD+ reconcile local priorities and needs with global mitigation benefits? Lessons from Angai Forest, Tanzania. Ecology and Society 17(1): 16. http://dx.doi.org/10.5751/ ES-04498-170116

Niedziałkowski, K., J. Paavola, and B. Jędrzejewska. 2012. Participation and protected areas governance: the impact of changing influence of local authorities on the conservation of the Białowieża Primeval Forest, Poland. Ecology and Society 17(1): 2. http://dx.doi.org/10.5751/ES-04461-170102

Paavola, J. 2007. Institutions and environmental governance: a reconceptualization. Ecological Economics 63:93-103. http://dx.doi.org/10.1016/j.ecolecon.2006.09.026

Paavola, J., A. Gouldson, and T. Kluvánková-Oravská. 2009. Interplay of actors, scales, frameworks and regimes in the governance of biodiversity. Environmental Policy and Governance 19:148-158. http://dx.doi.org/10.1002/eet.505

Raudsepp-Hearne, C., G. D. Peterson, and E. M. Bennett. 2010. Ecosystem service bundles for analyzing tradeoffs in diverse landscapes. Proceedings of the National Academy of Sciences of the United States of America 107:5242-5247. http://dx.doi.org/10.1073/pnas.0907284107

Rechkemmer, A., and L. von Falkenhayn. 2009. The human dimensions of global environmental change: ecosystem 
services, resilience, and governance. European Physical Journal Conferences 1:3-17. http://dx.doi.org/10.1140/ epjconf/e2009-00906-y

Reed, M. S., K. Hubacek, A. Bonn, T. P. Burt, J. Holden, L. C. Stringer, N. Beharry-Borg, S. Buckmaster, D. Chapman, P. J. Chapman, G. D. Clay, S. J. Cornell, A. J. Dougill, A. C. Evely, E. D. G. Fraser, N. Jin, B. J. Irvine, M. J. Kirkby, W. E. Kunin, C. Prell, C. H. Quinn, B. Slee, S. Stagl, M. Termansen, S. Thorp, and F. Worrall. 2013. Anticipating and managing future trade-offs and complementarities between ecosystem services. Ecology and Society 18(1): 5. http://dx. doi.org/10.5751/ES-04924-180105

Rendón Thompson, O. R., J. Paavola, J. R. Healey, J. P. G. Jones, T. R. Baker, and J. Torres. 2013. Reducing emissions from deforestation and forest degradation (REDD+): transaction costs of six Peruvian projects. Ecology and Society 18(1): 17. http://dx.doi.org/10.5751/ES-05239-180117

Robards, M. D., M. L. Schoon, C. L. Meek, and N. L. Engle. 2011. The importance of social drivers in the resilient provision of ecosystem services. Global Environmental Change 21:522-529. http://dx.doi.org/10.1016/j.

gloenvcha.2010.12.004

Soane, I. D., R. Scolozzi, A. Gretter, and K. Hubacek. 2012. Exploring panarchy in alpine grasslands: an application of adaptive cycle concepts to the conservation of a cultural landscape. Ecology and Society 17(3): 18. http://dx.doi. org/10.5751/ES-05085-170318

Turner, R. K., and G. C. Daily. 2008. The ecosystem services framework and natural capital conservation. Environmental and Resource Economics 39:25-35. http://dx.doi.org/10.1007/ s10640-007-9176-6

Turner, R. K., J. Paavola, P. Cooper, S. Farber, V. Jessamy, and S. Georgiou. 2003. Valuing nature: lessons learnt and future research directions. Ecological Economics 46:493-510. http://dx.doi.org/10.1016/S0921-8009(03)00189-7

Tuvendal, M., and T. Elmqvist. 2011. Ecosystem services linking social and ecological systems: river brownification and the response of downstream stakeholders. Ecology and Society 16(4): 21. http://dx.doi.org/10.5751/ES-04456-160421

van de Sand, I. 2012. Payments for ecosystem services in the context of adaptation to climate change. Ecology and Society 17(1): 11. http://dx.doi.org/10.5751/ES-04561-170111

Wallace, K. J. 2007. Classification of ecosystem services: problems and solutions. Biological Conservation 139:235-246. http://dx.doi.org/10.1016/j.biocon.2007.07.015

Watson, C., S. Mourato, and E. J. Milner-Gulland. 2013. Uncertain emission reductions from forest conservation: REDD in the Bale Mountains, Ethiopia. Ecology and Society 18(3): 6. http://dx.doi.org/10.5751/ES-05670-180306
Wesselink, A., J. Paavola, O. Fritsch, and O. Renn. 2011 Rationales for public participation in environmental policy and governance: practitioners' perspectives. Environment \& Planning A 43:2688-2704. http://dx.doi.org/10.1068/a44161

Wondolleck, J. M., and S. L. Yaffee. 2000. Making collaboration work. Lessons from innovation in natural resource management. Island, Washington, D.C., USA. 